\title{
Article \\ Effects of $\beta$-Hydroxy $\beta$-Methylbutyric Supplementation in Combination with Conservative Non-Invasive Treatments in Athletes with Patellar Tendinopathy: A Pilot Study
}

\author{
Ángela Sánchez-Gómez ${ }^{1}$, Jose Manuel Jurado-Castro ${ }^{2,3}{ }^{\mathbb{D}}$, Fernando Mata ${ }^{4}$ (D), Antonio Jesús Sánchez-Oliver ${ }^{5,6, *(\mathbb{D})}$ \\ and Raúl Domínguez ${ }^{5,6}$ (D)
}

1 Departamento de Enfermería Farmacología y Fisioterapia, Facultad de Medicina y Enfermería, Universidad de Córdoba, 14004 Córdoba, Spain; asgomez@uco.es

2 Metabolism and Investigation Unit, Maimonides Biomedical Research Institute of Cordoba (IMIBIC), Reina Sofia University Hospital, University of Cordoba, 14004 Córdoba, Spain; juradox@gmail.com

3 Centro Adscrito a la Universidad de Sevilla, Escuela Universitaria de Osuna, 41640 Osuna, Spain

4 Centro de Estudios Avanzados en Nutrición, 14010 Córdoba, Spain; fmataor@gmail.com

5 Departamento de Motricidad Humana y Rendimiento Deportivo, Universidad de Sevilla, 41013 Seville, Spain; rdherrera@us.es

6 Studies Research Group in Neuromuscular Responses (GEPREN), University of Lavras, Lavras 37200-000, Brazil

* Correspondence: sanchezoliver@us.es; Tel.: +0034-656305480

check for updates

Citation: Sánchez-Gómez, Á.; Jurado-Castro, J.M.; Mata, F.; Sánchez-Oliver, A.J.; Domínguez, R. Effects of $\beta$-Hydroxy

$\beta$-Methylbutyric Supplementation in Combination with Conservative Non-Invasive Treatments in Athletes with Patellar Tendinopathy: A Pilot Study. Int. J. Environ. Res. Public Health 2022, 19, 471. https://doi.org/ 10.3390/ijerph19010471

Academic Editor: Paul B.

Tchounwou

Received: 1 December 2021

Accepted: 29 December 2021

Published: 1 January 2022

Publisher's Note: MDPI stays neutral with regard to jurisdictional claims in published maps and institutional affiliations.

Copyright: (c) 2022 by the authors. Licensee MDPI, Basel, Switzerland. This article is an open access article distributed under the terms and conditions of the Creative Commons Attribution (CC BY) license (https:/ / creativecommons.org/licenses/by/ $4.0 /)$.

\begin{abstract}
The aim of the present study was to analyze the effect of conservative non-invasive treatments based on eccentric training, stretching and extracorporeal shock wave therapy (ESWT) supplemented with $\beta$-Hydroxy $\beta$-methylbutyric (HMB) or placebo (PLAC) on body composition, pain and muscular function (jump ability, muscular power and muscular strength) in athletes with patellar tendinopathy (PT). In a double-blind randomized trial, 8 athletes ( 4 males and 4 females) performed a physical rehabilitation for 4 weeks. They were randomly divided into two experimental groups (two males and two females in each one) that ingested HMB (HMBG) or PLAC (PLACG). In pre- and post-intervention were assessed body composition, pain, countermovement jump (CMJ), back-squat (BS) for analyzing peak power (W) $\left(\mathrm{PP}_{\mathrm{PP}}\right)$, load $(\mathrm{kg})$ associated to $\mathrm{PP}_{\mathrm{PP}}\left(\mathrm{PP}_{\mathrm{KG}}\right)$ and mean velocity $(\mathrm{m} / \mathrm{s})\left(\mathrm{PP}_{\mathrm{MV}}\right)$ in addition to a 5-RM leg extension tests. An interaction intervention supplementation $\left(p=0.049 ; \eta_{\mathrm{p}}^{2}=0.774\right)$ was observed in the height reached in the CMJ as an intervention effect in PPPP detected for the HMBG $(p=0.049)$. In addition, an enhancement in PPKG $\left(p=0.028 ; \eta^{2} p=0.842\right)$ was detected in the intervention, but not in PPMV, as an increase in the intervention in the 5-RM test $\left(p=0.001 ; \eta^{2}{ }_{p}=0.981\right)$ was observed. No changes were noted on body composition or pain $(p>0.05)$. The combination of eccentric training with stretching and ESWT increased concentric muscular power and strength after 4 weeks without changes in body lean mass or pain. In addition, HMB supplementation could enhance the power muscular performance in athletes with PT, optimizing the intervention adaptions.
\end{abstract}

Keywords: recovery; injury; patellar tendinopathy; rehabilitation; supplement; sport nutrition

\section{Introduction}

Patellar tendinopathy (PT) is one of the most common musculoskeletal pain problems associated with sports, particularly those that includes jumping activities [1], including a prevalence $\sim 50 \%$ in high-level volleyball [2] and basketball players [3], being frequently called "jumper's knee" [4]. PT is basically caused by tendon overload [5] and affects the insertion of the patellar tendon just under the apex of the patella [6]. PT is characterized by the increased presence of fibroblasts, vascular hyperplasia, increased amounts of proteoglycans and glycosaminoglycans, disorganized collagen, absence of inflammatory cells and prostaglandin [7]. It is accompanied by a symptomatology of pain in the anterior aspect 
of the knee and limits the athlete's functional capacity and, therefore, the performance of sports actions that over-solicit the tendon [8].

Invasive strategies, such as platelet-rich plasma [9], intratissue percutaneous electrolysis (EPI), ultrasound-guided galvanic electrolysis technique (USGET) and high-volume infiltrations $[10,11]$, have shown diverse results in PT treatment. Conservative non-invasive treatments, such as ultrasound [12] and extracorporeal shockwave therapy (ESWT) [13] and, mainly, eccentric exercise [14-16] and stretching [17], constitute feasible alternatives to improve injured patella in athletes. For PT rehabilitation, the decline squat is the most commonly used type of specific eccentric exercise used [5]. During eccentric contractions, the external force is greater than that being exerted by the muscle and hence lead to the muscle lengthening while tension is generated [18]. After a single session of eccentric exercise, nonadapted muscles experienced a delayed onset muscle soreness (DOMS), which produces local pain, reducing muscle functionality by decreasing maximal voluntary contraction and range of movement (ROM) [19], alters protein synthesis and degradation, and stimulates an inflammatory response [20]. However, repeated eccentric bouts (eccentric training) foster an adaption to exercise by which the muscles involved respond more efficiently to DOMS and its side effects [21]. Besides, eccentric training promotes the alignment of collagen fibers, generating more resistant fibers, stimulating the fibroblasts activity and preventing adherences during the healing stage between the tendon and the adjacent tissues [22]. The combination of eccentric training and stretching has demonstrated a higher effect in the reduction of pain in athletes with PT [23]. In addition, ESWT could generate high forces on the tendon producing analgesic benefits by the mechanical disintegration of calcium deposits and the stimulation of tissue repair $[24,25]$ and optimize a conservative treatment in athletes with PT [26,27].

Different studies have proposed that through nutrition it is possible to optimize physical rehabilitation in sports injuries [28,29]. Specifically, certain sports supplements have been found to be effective in recovering from injuries or after long periods of immobilization. However, less attention has been paid to the supplementation effects on musculoskeletal injuries [30]. $\beta$-Hydroxy $\beta$-methylbutyric (HMB) is a leucine metabolite resulting from this essential amino acid transamination to $\alpha$-ketoisocaproic acid $(\alpha-\mathrm{KIC})$, which is subsequently converted into HMB by dioxygenase [31]. HMB has been proposed as an ergogenic sports supplement for the maintenance of the nitrogen balance based on its anabolic and catabolic effects. In vitro, it has been reported that HMB enhances protein synthesis by its involvement in the mammalian target of the rapamycin (mTOR) pathway [32], partially explained by an increased activity in the muscle of the growth hormone/IGF-1 axis that improves protein synthesis via mTOR activation [33]. In addition, in myoblast cultures, the addition of HMB increases mRNA levels of markers of activated satellite cells and protein levels of muscle differentiation factors [34]. Moreover, by antagonism of the ubiquitin-proteasome pathway, HMB could diminish the rate of degradation of intracellular proteins [35] and increase the cell membrane integrity by its effect as a precursor of intracellular cholesterol [36]. Although athlethes frequently consume HMB supplements to enhance body composition (increasing lean mass and reducing fat mass), two different meta-analyses have reported a non-significant effect of HMB supplementation on body composition in athletes $[37,38]$. Its absence of effects on highly-trained athletes has been explained by a lower effect on trained athletes and a higher susceptibility in untrained individuals, especially during the initial stages of training when untrained subjects present higher levels of muscle damage compared with the trained population [39]. In fact, HMB supplementation has demonstrated benefits to preserve or improve muscle mass and muscular strength in older people with muscle loss [40] and function as an alternative in the treatment of sarcopenic obesity in the elderly [41].

To date, no study has evaluated the effect of a nutritional intervention in athletes diagnosed with PT who undergo controlled physical rehabilitation. Physical rehabilitation of PT based on eccentric training causes a high level of degradation of muscle protein, such as promoting the synthesis of muscle proteins and collagen and the possible effects 
of HMB supplementation when high catabolic situations exist. Therefore, the aim of the present study was to analyze the effect of 4 weeks of physical rehabilitation that combined eccentric training, stretching and ESWT, supplemented with an HMB or placebo (PLAC) supplementation on athletes diagnosed with PT on body composition, perceived pain, and muscular function (jump ability, muscular power and muscular strength).

\section{Materials and Methods}

\subsection{Experimental Design}

The study involved an experimental double-blind randomized trial in which 8 athletes (4 males and 4 females) undergoing a 4-week patellar tendinopathy rehabilitation program of home sessions, in addition to sessions supervised and treated by a collegiate physiotherapist. Participants were randomly divided in a placebo supplementation intervention group (PLACG) or HMB supplementation intervention group (HMBG). Randomization to each experimental group (HMBG and PLACG), for ensuring a homogeneous sex-participants distribution (two males and two females in each group), was performed using Research Randomizer (www.randomizer.org). At the beginning and at the end of the study, the athletes performed an experimental session in the laboratory, - where anthropometric measurements, pain, jump ability, muscular power and strength were measured (see Figure 1). Participation in the study was voluntary and all the participants were informed of the study protocol, schedule and nature of the supplementation, the exercises, and the tests to be performed before signing an informed consent form. The study protocol adhered to the Declaration of Helsinki and was approved by an Ethics Committee (code: UI1-PI017).

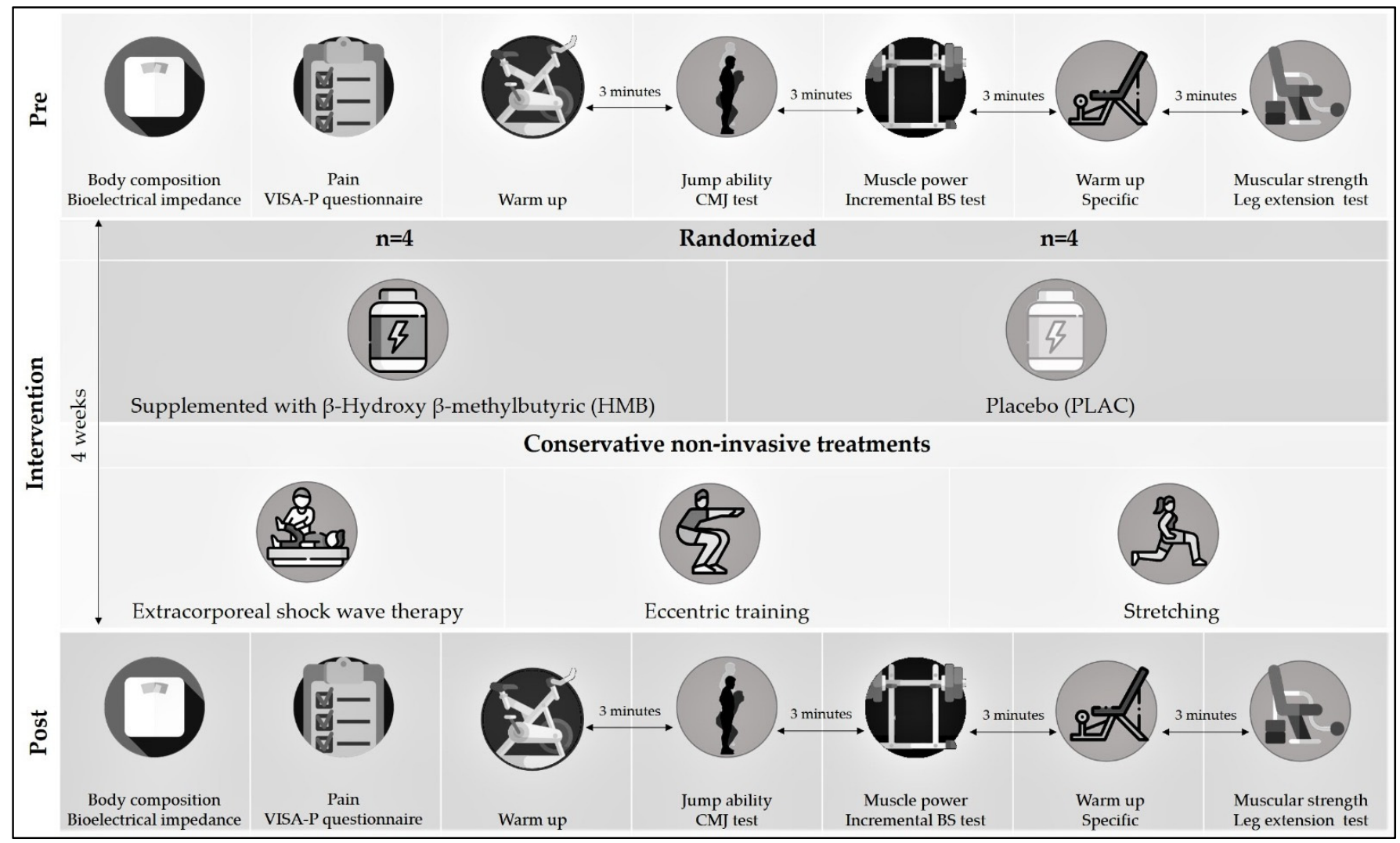

Figure 1. Experimental design.

BS: back squat; CMJ: countermovement jump; VISA-P: Victorian Institute of Sport Assessment-Patella. 


\subsection{Participants}

All the participants were federated athletes (including basketball, volleyball, handball, and athletics) who were diagnosed with patellar tendinopathy by a sports medicine doctor. They were recruited through direct contact with the federated sports club of the city of Córdoba (Spain). In addition to being federated athletes and being diagnosed with PT by a sports medicine doctor and a physiotherapist based on the criteria of Rio et al. (2015) [42], the participants had to fulfill the following inclusion criteria: (1) aged 18-49 years; (2) not having previously undergone knee surgery or analgesic or platelet-rich plasma infiltration; (3) not having consumed any substance that could affect their hormone levels or sport performance in the previous 3 months, such as sport supplements or steroids; (4) not having any food intolerance or allergy; (5) not being a smoker; (6) not having any cardiovascular, kidney or liver disorder.

\subsection{Supplementation}

HMB (3 g. day $\left.{ }^{-1}\right)$ in HMBG or PLAC ( $3 \mathrm{~g} \cdot \mathrm{day}^{-1}$ sucrose) in PLACG were ingested in three capsules 60 minutes before exercise, according to the optimal dose and timing of this supplement [43]. To ensure blinding, the supplements were provided in \#1 nontransparent red capsules (Guinama S.L.U, 0044634, La Pobla de Valbona, Spain) that were prepared using a semi-automatic manual filling machine Capsunorm 2000 (Miranda de Ebro, Spain), guaranteeing food safety measures in the laboratory. In addition, to avoid any possible ergogenic effect of caffeine during the assessment sessions, a list of foods rich in caffeine (e.g., coffee, tea, tea soft drinks, cola drinks, mate, energy drinks, chocolate drinks and chocolate) was provided to all participants to avoid its consumption $24 \mathrm{~h}$ prior.

\subsection{Physical Rehabilitation}

The rehabilitation program was combined with an eccentric training program and extracorporeal ESWT. During the entirety of the intervention, the participants performed single-legged eccentric decline squat exercises, knee exercises (decline squat), with 3 sets of 10 repetitions being performed daily. The exercise involved standing on the painful leg, performed in a declined plane $\left(25^{\circ}\right)$ and maintaining an upright trunk while slowly squatting down in $2 \mathrm{sec}$ until reaching a flexion of $90^{\circ}$, which guarantees the achievement point of maximum tension ( $60^{\circ}$ in the patellar tendon) [44]. This exercise was complemented with a weight vest of $5 \mathrm{~kg}$ when the visual analogue scale (VAS) for pain assessment obtained a score of 3 points or less [45]. The eccentric training program was performed twice a day with 2 min of recovery between sets. Before and after eccentric training, the participants performed statics stretching based on research that reported gains when stretching and eccentric training was combined in patellar tendinopathy rehabilitation [23]. In addition, the participants received three sessions (with a 1-week interval) of ESWT and manual therapy in the clinic with deep manual massage of the tendon and quadriceps unloading (of both legs). ESWT treatment was applied using a Storz Duolith SD1 (Storz Medical AG, Tägerwilen, Switzerland) in sessions divided into three phases (the third was performed in quadriceps, to remove tension in the muscular belly) [46]: R-SW 15 bar, 1500 pulses, frequency $10 \mathrm{~Hz}$; R-SW 2 bar, 2000 pulses, frequency 15 Hz; V-ACTOR 2 bar, 2500 pulses, frequency $25 \mathrm{~Hz}$.

\subsection{Body Composition Assessment}

The anthropometrics measures were carried out with the participants barefoot and in underwear. The body height was measured with the participants erect and their head in the Francfort's plane using a stadiometer (Seca 214, Hamburg, Germany), while the body composition was measured using a bioelectrical impedance analysis (Tanita MC-780MA, Tanita Corporation, Japan), ensuring standardized conditions for bioelectrical impedance measurement [47]. The following variables were analyzed: body mass, body mass index (BMI), body fat mass $(\mathrm{kg}), \%$ body fat, body muscle mass $(\mathrm{kg})$ and \% body muscle mass. 


\subsection{Pain Assessment}

For the analysis of pain, the participants completed the Victorian Institute of Sport Assessment-Patella (VISA-P questionnaire), the only disease-specific instrument to measure PT symptoms that impact function and the ability to play sport [48].

\subsection{Muscular Function Assessment}

The jump ability was measured by the countermovement jump (CMJ) test. This test began with a warm-up, which started with 10 minutes of pedaling on the cycle ergometer (the first 4 minutes at a free intensity and the next 6 minutes at $75 \%$ of the maximum heart rate (Polar H10, Kempele, Finland)). After a 2 minutes rest, the participants performed five CMJs of increasing intensity. After a recovery of 3 minutes, the initiated test consisted of $3 \mathrm{CMJs}$, with a recovery period of 45 seconds between jumps. During the jump, an evaluator was at a distance of $1.5 \mathrm{~m}$ in the frontal plane to record the jump with a mobile (cell) phone (iPhone 7; Apple, Cupertino, CA, USA) at a sampling rate of $240 \mathrm{~Hz}$, using the My Jump app. My Jump is an application which has indicated a good validity with a force platform $(r=0.995)$ [49]. The maximum height reached was registered.

Muscle power was assessed by power produced in a back-squat (BS) exercise, in an incremental BS test, analyzing movement velocity and power during BS with a linear position transducer (v.4.1, Speed4Lift, Madrid, Spain) which has indicated a good validity with respect to the gold-standard (Trio-OptiTrack) $(r=0.95-1.00)$ [50]. Based on previous studies [51], the incremental BS consisted of 2 repetitions, with 2 seconds of rest between repetitions, lifting a $20 \mathrm{~kg}$ load at a maximum velocity of displacement for optimal muscle activation. Then, the load was increased, and the bar mean velocity measured displacement was under $0.80 \mathrm{~m} / \mathrm{s}$. When the mean velocity was above $0.80 \mathrm{~m} / \mathrm{s}$, the participants increased the load by $5 \mathrm{~kg}$. The test finished after reaching the peak power (PP). The variables analyzed were the load $(\mathrm{kg})$ lifted $\left(\mathrm{PP}_{\mathrm{KG}}\right)$, mean velocity $(\mathrm{m} / \mathrm{s})(\mathrm{PP} \mathrm{MV})$, and peak power $(\mathrm{W})\left(\mathrm{PP} \mathrm{pp}_{\mathrm{p}}\right)$ reached in the repetition where $\mathrm{PP}$ was registered.

Muscular strength was assessed by a 5-repetition maximum (5-RM) test in leg extension (Selection Leg Extension, Technogym, Cesena, Italy). The specific warm-up consisted of 10 repetitions with a load corresponding to 50\% of the estimated 10-RM (based on the individual assessment). After 3 minutes of recovery, the participants initiated the test based on individual assessment and there was a break of 2 minutes when the participants selected a load which could lift more or less than 5-RM [52].

\subsection{Statistical Analysis}

Normality distribution was contrasted with Shapiro-Wilk's test and equality of variances with Levene's test. For analysing the anthropometrics, perception of pain, jump ability and muscular performance variables, separate $2 \times 2$ independent analyses of variance for repeated measures (ANOVA-RM) were applied for each variable. Supplementation group (HMBG vs. PLACG) was introduced as an inter-subject factor, whereas intervention (PRE vs. POST) was used as an intra-subject factor. ANOVA-RM effect sizes (ES) were calculated using partial eta squared $\left(\eta^{2} \mathrm{p}\right)$, considering small to be under 0.25 , medium, the range $0.26-0.63$ and large, above 0.63 [53]. A pairwise comparison was performed with the Bonferroni post hoc test. Statistical significance was set at $p<0.05$. All the statistical tests were performed using the Statistical Package for Social Sciences (version 20.0 for Mac, SPSS $^{\text {TM }}$ Inc., Chicago, IL, USA).

\section{Results}

No differences were observed in the analysis of the anthropometric variables during the intervention, supplementation, or intervention supplementation $(p>0.05)$ (see Table 1$)$. 
Table 1. Anthropometric variables result.

\begin{tabular}{|c|c|c|c|c|c|c|}
\hline \multirow{2}{*}{ Variable } & \multirow{2}{*}{ Supplementation } & \multicolumn{2}{|c|}{ Intervention } & \multirow{2}{*}{$\begin{array}{c}p \text {-Value } \\
\text { Intervention }\end{array}$} & \multirow{2}{*}{$\begin{array}{c}p \text {-Value } \\
\text { Supplementation }\end{array}$} & \multirow{2}{*}{$\begin{array}{c}p \text {-Value } \\
\text { Intervention. } \\
\text { Supplementation }\end{array}$} \\
\hline & & PRE & POST & & & \\
\hline \multirow{2}{*}{$\begin{array}{l}\text { Body mass } \\
\quad(\mathrm{kg})\end{array}$} & HMBG & $79.7 \pm 9.3$ & $80.3 \pm 10.7$ & \multirow[b]{2}{*}{0.950} & \multirow[b]{2}{*}{0.924} & \multirow[b]{2}{*}{0.456} \\
\hline & PLACG & $79.5 \pm 7.3$ & $78.8 \pm 8.4$ & & & \\
\hline \multirow{2}{*}{ BMI } & HMBG & $24.3 \pm 2.7$ & $25.1 \pm 2.1$ & \multirow{2}{*}{0.387} & \multirow{2}{*}{0.927} & \multirow{2}{*}{0.367} \\
\hline & PLACG & $24.9 \pm 1.9$ & $24.7 \pm 2.1$ & & & \\
\hline \multirow{2}{*}{$\begin{array}{l}\text { Body fat } \\
\text { mass }(\mathrm{kg})\end{array}$} & HMBG & $13.9 \pm 7.2$ & $14.8 \pm 6.9$ & \multirow[b]{2}{*}{0.223} & \multirow[b]{2}{*}{0.984} & \multirow[b]{2}{*}{0.168} \\
\hline & PLACG & $18.2 \pm 5.6$ & $18.6 \pm 5.4$ & & & \\
\hline \%Body & HMBG & $18.2 \pm 11.0$ & $18.9 \pm 10.0$ & \multirow{2}{*}{0.160} & \multirow{2}{*}{0.876} & \multirow{2}{*}{0.371} \\
\hline fat mass & PLACG & $22.8 \pm 7.0$ & $23.6 \pm 7.0$ & & & \\
\hline Body muscle & HMBG & $63.3 \pm 14.3$ & $62.2 \pm 13.1$ & \multirow{2}{*}{0.460} & \multirow{2}{*}{0.621} & \multirow{2}{*}{0.277} \\
\hline mass (kg) & PLACG & $57.8 \pm 7.9$ & $57.7 \pm 7.1$ & & & \\
\hline \%Body & HMBG & $77.7 \pm 10.6$ & $77.1 \pm 9.8$ & \multirow{2}{*}{0.710} & \multirow{2}{*}{0.544} & \multirow{2}{*}{0.888} \\
\hline muscle mass & PLACG & $73.1 \pm 7.0$ & $72.8 \pm 6.4$ & & & \\
\hline
\end{tabular}

Data presented as $\mathrm{M} \pm \mathrm{SD}$. BMI: body mass index; HMBG: $\beta$-Hydroxy $\beta$-methylbutyric group; PLACG: placebo group.

In the perception of pain, neither was reported any effect for intervention $(p=0.080$; $\left.\eta^{2} \mathrm{p}=0.694\right)$, supplementation $\left(p=0.251 ; \eta^{2} \mathrm{p}=0.401\right)$ nor intervention $\cdot$ supplementation $\left(p=0.418 ; \eta^{2} p=0.226\right)($ see Figure 2$)$.

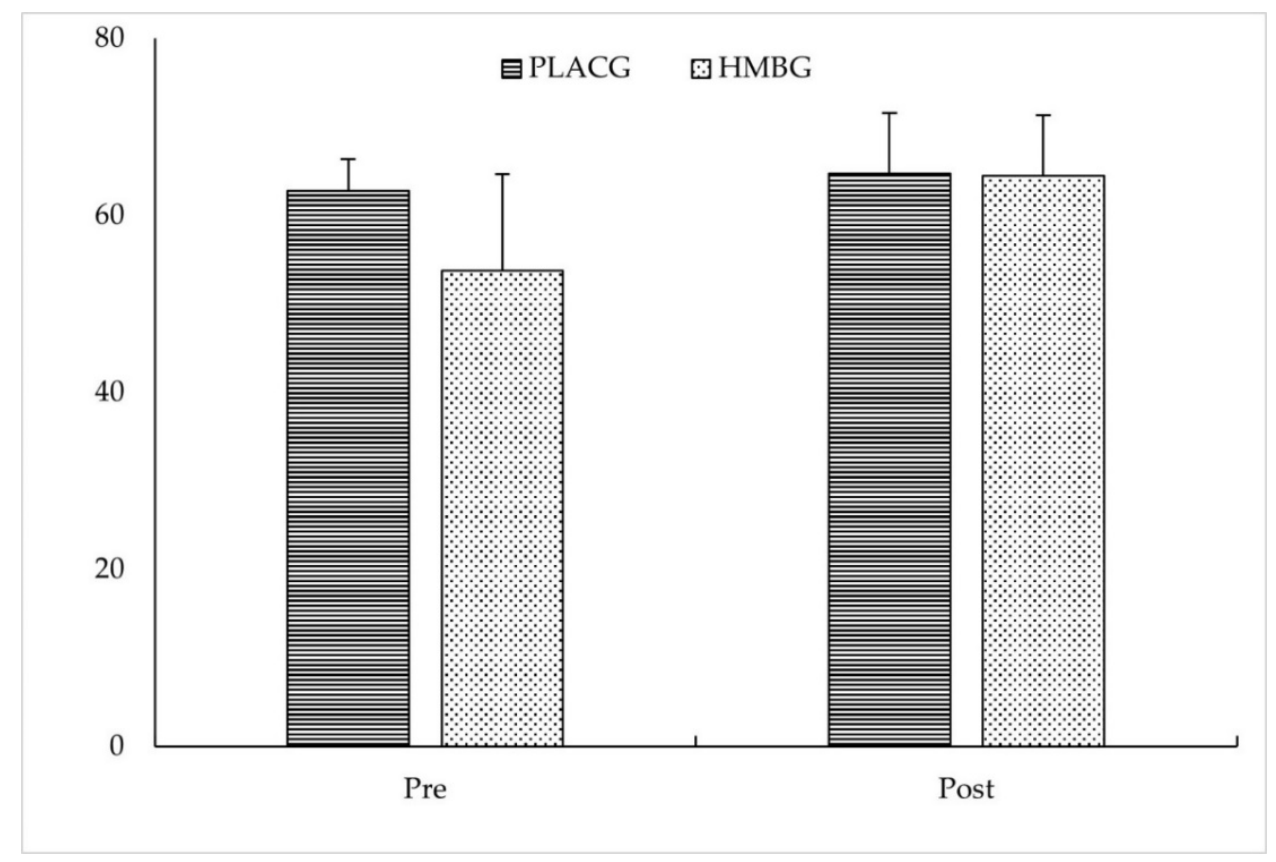

Figure 2. Subjective pain perceived by the VISA-P score.

HMBG: $\beta$-Hydroxy $\beta$-methylbutyric group; PLACG: placebo group; VISA-P: Victorian Institute of Sport Assessment-Patella.

The performance in the jump ability did not report differences in intervention $(p=0.085)$ or supplementation $(p=0.694)$; however, a significant effect for the interaction intervention supplementation $\left(p=0.049 ; \eta^{2} p=0.774\right)$ was observed. In the incremental BS tests, an enhancement was noted in the post intervention in $\mathrm{PP}_{\mathrm{KG}}(68.0 \pm 5.1 \mathrm{~kg}$ vs. $62.2 \pm 4.0 \mathrm{~kg}$; $\left.p=0.028 ; \eta^{2}{ }_{p}=0.842\right)$, with no differences for the supplementation factor $(p=0.948)$ or the interaction of intervention supplementation $(p=0.335)$. In addition, higher values of $\mathrm{PP}_{\mathrm{PP}}$ in the post-intervention were recorded $(544.8 \pm 40.2 \mathrm{~W}$ vs. $467.3 \pm 40.5 \mathrm{~W} ; p=0.002$; $\left.\eta^{2} \mathrm{p}=0.971\right)$, with statistical differences detected only in the HMBG $(p=0.049)$. No dif- 
ferences were observed for supplementation $(p=0.842)$ or the interaction intervention supplementation $(p=0.142)$ in $\mathrm{PP}_{\mathrm{PP}}$. Nor were any differences noted for intervention $(p=0.296)$, supplementation $(p=0.268)$ or intervention supplementation $(p=0.796)$ in $\mathrm{PP}_{\mathrm{MV}}$. As to muscular strength, a significant decrease in the weight loaded in the 5-RM test was observed $\left(74.1 \pm 2.4 \mathrm{~kg}\right.$ vs. $\left.64.4 \pm 1.6 \mathrm{~kg} ; p=0.001 ; \eta^{2} \mathrm{p}=0.981\right)$, with differences detected as PLAG ( $p=0.030)$ like in the HMBG $(p=0.015)$ (see Table 2$)$.

Table 2. Performance variables in the CMJ, BS incremental test and 5-RM test.

\begin{tabular}{|c|c|c|c|c|c|c|}
\hline \multirow{2}{*}{ Variable } & \multirow{2}{*}{ Supplementation } & \multicolumn{2}{|c|}{ Intervention } & \multirow{2}{*}{$\begin{array}{c}p \text {-Value } \\
\text { Intervention }\end{array}$} & \multirow{2}{*}{$\begin{array}{c}p \text {-Value } \\
\text { Supplementation }\end{array}$} & \multirow{2}{*}{$\begin{array}{c}p \text {-Value } \\
\text { Intervention. } \\
\text { Supplementation }\end{array}$} \\
\hline & & PRE & POST & & & \\
\hline \multirow{2}{*}{$\mathrm{CMJ}(\mathrm{cm})$} & HMBG & $38.1 \pm 10.4$ & $41.1 \pm 11.7$ & \multirow{2}{*}{0.850} & \multirow{2}{*}{0.694} & \multirow{2}{*}{$0.049 \lambda$} \\
\hline & PLACG & $37.0 \pm 6.0$ & $35.6 \pm 4.7$ & & & \\
\hline \multirow{2}{*}{$\mathrm{PP}_{\mathrm{KG}}(\mathrm{kg})$} & HMBG & $59.4 \pm 13.0$ & $71.5 \pm 17.0$ & \multirow{2}{*}{$0.028 *$} & \multirow{2}{*}{0.948} & \multirow{2}{*}{0.335} \\
\hline & PLACG & $65.0 \pm 17.8$ & $64.4 \pm 11.6$ & & & \\
\hline \multirow{2}{*}{$\mathrm{PP}_{\mathrm{MV}}\left(\mathrm{m} \cdot \mathrm{s}^{-1}\right)$} & HMBG & $0.78 \pm 0.12$ & $0.81 \pm 0.05$ & \multirow{2}{*}{0.296} & \multirow{2}{*}{0.268} & \multirow{2}{*}{0.796} \\
\hline & PLACG & $0.74 \pm 0.04$ & $0.79 \pm 0.03$ & & & \\
\hline \multirow{2}{*}{$\mathrm{PP}_{\mathrm{PP}}(\mathrm{W})$} & HMBG & $455.5 \pm 105.5 \#$ & $575.3 \pm 138.8$ & \multirow{2}{*}{$0.002 *$} & \multirow{2}{*}{0.842} & \multirow{2}{*}{0.142} \\
\hline & PLACG & $479.0 \pm 125.3$ & $514.4 \pm 107.0$ & & & \\
\hline \multirow{2}{*}{ 5-RM test (kg) } & HMBG & $55.0 \pm 4.1 \#$ & $68.1 \pm 3.1$ & \multirow{2}{*}{0.001 * } & \multirow{2}{*}{0.081} & \multirow{2}{*}{0.184} \\
\hline & PLACG & $73.8 \pm 10.5 \#$ & $80.0 \pm 9.4$ & & & \\
\hline
\end{tabular}

Data presented as $\mathrm{M} \pm$ SD. BS: back squat; CMJ: countermovement jump; HMBG: $\beta$-Hydroxy $\beta$-methylbutyric group; PLACG: placebo group; PPKG: peak power kg lifted; PPMV: peak power mean velocity; PPPP: peak power; 5-RM: five-repetition maximum; \#: significant effect of a group in the post-intervention vs pre-intervention; *: significant effect for intervention; $\lambda$ : significant effect for intervention supplementation.

\section{Discussion}

The main findings of this study were that height reached in the CMJ presented an interaction from intervention supplementation $\left(p=0.049 ; \eta_{p}^{2}=0.774\right)$ as an effect of the intervention in PP $P_{P P}$ that was only detected in the HMBG $(p=0.049)$. In addition, an enhancement in $\mathrm{PP}_{\mathrm{KG}}\left(p=0.028 ; \eta^{2} \mathrm{p}=0.842\right)$ and in the load weighted in the 5-RM test $\left(p=0.001 ; \eta^{2}=0.981\right)$ was detected for the intervention. In addition, an important finding is that these changes in muscular function were not accompanied by any modification in body composition variables $(p>0.05)$ and pain, measured by the VISA-P punctuation $(p>0.05)$.

Regarding the muscular strength, this study observed an enhancement in the 5-RM leg extension test after 4-weeks intervention of eccentric training combined with stretching and ESWT. This result is similar to another previous study that reported an enhancement of one repetition maximum (1-RM) on leg press after 20 weeks of eccentric training of athletes with PT [54]. Nevertheless, Romero-Rodríguez et al. (2010) found an improvement on maximal eccentric, but not concentric force after 6-weeks of eccentric training using a flywheel device in athletes with PT. These authors suggested a specific effect of eccentric training on the eccentric force [55]. However, the leg extension exercise employed in our study, the leg press exercise selected by Bahr et al. (2006), analyzes concentric strength [54]. Thus, our results confirm that, during eccentric training in athletes with PT, it could be effective to increase the concentric strength.

In relation to muscle power, two previous studies analyzed the effect of an eccentric training program in subjects with PT through an isokinetic exercise [56,57]. In the study carried out by Biernat et al. (2014) no effect was observed in the knee flexion or extension in an isokinetic machine after 12 or 24 weeks [56], whereas Frohm et al. (2007) observed an increased power production in concentric isokinetics strength at $90^{\circ} \mathrm{C}$ after 12 weeks of decline squat eccentric training [57]. In the present study, muscle power was considered to be one of the major determinants of sport performance in several sport modalities [58,59], because a common target for athletes is to apply maximum power levels to a given work load [51]. We, therefore, selected the progressive incremental BS test to determine the maximal concentric power, recognizing that the power output reflects the relation between the load and the movement velocity in the BS execution. In our research, an increase in 
$\mathrm{PP}_{\mathrm{KG}}$ and $\mathrm{PP}_{\mathrm{PP}}$, but not in $\mathrm{PP}_{\mathrm{MV}}$, was observed after the intervention. These results reflect an enhancement in the power explained by an increase of the force, but not in movement velocity. The study's results were in accordance with previous works that reported an enhancement of $\mathrm{PP}_{\mathrm{PP}}$ occurring at a same $\mathrm{PP}_{\mathrm{MV}}$, but with a higher $\mathrm{PP}_{\mathrm{KG}}$, considering the velocity of movement at a load corresponding to peak power to be constant [51]. However, the most important finding of this study was an interaction from intervention supplementation $\left(p=0.049 ; \eta^{2}=0.774\right)$ in the height reached in the CMJ. Previously, different studies did not observe any effect on the height reached in the CMJ after 12, 20 or 24 weeks of eccentric training based on decline squat $[54,56]$, or after 6 weeks with a flywheel device [55].

An injured tendon presents a loss of the longitudinal collagen fibers, an abruption in the collagen bundles and a relative expansion of the tendon [24,27]. The discontinuous and disorganized collagen fibers of the injured tendon reflect a loss in the functionality of this tissue $[27,60]$. A lower tendon stiffness and Young's modulus, compared with healthy controls, has been observed in volleyball players with PT [61], while other studies have reported a tendon strain in subjects with PT [62]. A decrease in tendon stiffness increases the deformation to a determined force and, therefore, might be a potential cause of tendinopathy [63] and influence, over time, the muscle response (electromechanical delay) to applied force [64], which is another important risk factor for musculoskeletal injuries [65]. An effect on stiffness implies an alteration of the joint moment-angle and moment-velocity properties [66] and could explain the decreasing knee extensor in athletes with PT [67]. Thus, impairments in the muscular strength of the knee extensor muscles may be caused by a decrease in the energy-absorption capacity of the muscle-tendon complex [68]. The increased mechanic load causes an increase in the synthesis collagen [69,70]; the load caused by eccentric training could increase the content of collagen and foster the alignment of collagen fibers. This would increase the resistance of fibers and the activity of the fibroblasts and prevent adherences during the healing stage between the tendon and the adjacent tissues [22].

Eccentric training based on the $25^{\circ} \mathrm{C}$ decline squat selected in our study has shown an increased knee extensor electromyography (EMG) compared to the squat performed on a flat surface [71]. The decline squat has allowed for optimizing the muscular strength of eccentric training [71] and could increase the patellar tendon strain. Moreover, it has been observed how, in the treatment of PT, interventions based on eccentric exercises seem to have shown a greater efficacy in reducing knee pain compared to an intervention based on concentric exercises [72]. In addition to the exercise selected ( $25^{\circ} \mathrm{C}$ decline squat), we have included stretching training because an impairment flexibility in the quadriceps [73] and hamstrings has been reported $[73,74]$ in athletes with PT. Limited hamstrings flexibility has been proposed as a factor that increases knee extensor muscles to overcome the passive resistance offered by the hamstrings $[75,76]$, whereas flexibility deficits in knee extensors have presented strong abnormalities in the patellar tendon $[77,78]$. Only one study to date [23], with a methodology similar to ours, has investigated the effectiveness of eccentric training with static stretching exercises in the management of PT for 4 weeks, obtaining a greater effect of reducing pain and improving function at the end of treatment and at the follow-up when the participants performed additional static stretching. In the intervention proposed in our study, a treatment with ESWT was also carried out. ESWT has been effective at reducing muscular pain in athletes with PT by its capacity to stimulate fibroblast activity [79], type I collagen production, and tissue remodeling [80], as well as the inhibiting afferent pain-receptor function [81]. The combination of eccentric training, stretching and ESWT could potentiate the effect of this intervention on the muscular improvement in the 5-RM test and the PP in the BS tests even in the CMJ in the HMBG.

The interaction of intervention supplementation in the height reached in the CMJ and the improvement in the $\mathrm{PP}_{\mathrm{PP}}$ in the HMBG, but not in the PLAG, suggests a positive effect of this supplement in combination with supervised physical therapy. Four different studies have analyzed the effect of HMB after a single eccentric training session [82-84]. 
Paddon-Jones et al. (2001) did not observe any effect during 6 days of supplementation ( $3.4 \mathrm{~g} /$ day) in a session consisting of 3 sets of 6 maximal eccentric elbow curls on an isokinetic peak torque or DOMS [83]. Nevertheless, in a study with the same protocol supplementation ( $3 \mathrm{~g} /$ day during 6 days), Knitter et al. (2000) observed a significantly lower creatine kinase $(\mathrm{CK})$ and lactate dehydrogenase $(\mathrm{LDH})$ response over 4 days after a 20-km run on moderately-trained athletes [82], whereas Van Someren et al. (2005) observed a lower decrease in the maximal concentric strength and the CK and DOMS peak after an eccentric session consisting of 3 sets of 10 repetitions of biceps curl unilaterally at a rate of 10 seconds for each repetition, with a load corresponding to 70\% 1-RM [84]. As the CK and LDH in blood are considered commonly used markers of sarcolemma damage, the previous studies suggest that HMB supplementation over 2 weeks could decrease the muscle damage as a component within the muscle cell membrane [85] or as a precursor of intracellular cholesterol that enhances the cell membrane integrity [36]. As it is considered that eccentric exercise-induced muscle damage (EIMD) and acute losses in muscle strength, imbalances in muscle protein breakdown and protein synthesis [86], the anticatabolic effect of HMB could improve training adaptations [30]. In fact, a recent study carried out by Tsuchiya et al. (2019) observed an interaction of time-supplementation in subjects who were supplemented with HMB ( $3 \mathrm{~g} /$ day) during 2 and 4 weeks in the maximal voluntary isometric contraction torque, range of motion, DOMS and muscle stiffness after a session consisting of 6 sets of 10 maximal voluntary eccentric contraction on elbow flexors [87]. Hence, mediated by muscular stiffness, HMB could affect the acute lower muscular power production after an eccentric session. In fact, the authors speculate that a protection of the muscle membrane and muscle satellite cells may inhibit the decrease in muscle performance after eccentric exercise [87]. Given that an increase in the mechanic load causes a rise of synthesis collagen $[69,70]$ and the positive correlation between collagen content of tendon and tendon stiffness $[69,70,88]$, it is possible that the improvement in the recovery after each eccentric session could increase the muscular and tendon adaptation that causes an enhancement in the power lower limb observed in the CMJ and BS test in the athletes of HMBG. Also, according to the different meta-analysis performed on highly-trained athletes [37,38], HMB supplementation does not affect body composition. Our results inform that no difference in body composition is detected nor HMBG nor PLACG. Therefore, it is possible that eccentric training is effective in maintaining lean mass in athletes with PT. Regardless, it is necessary to consider that hypertrophy is not detected before 5 weeks of an eccentric training program [89] and that HMB could increase the neuromuscular adaptations during physical rehabilitation of PT. Regarding pain, different studies have observed a positive effect of eccentric training on the increase of the VISA scale above 6 [55], 12 [57,90] and 20 [54] weeks. Considering our results, where no positive effect for diminishing pain for the intervention $\left(p=0.080 ; \eta^{2}=0.694\right)$ was observed, it is possible that the duration of the intervention (4 weeks) could be too little to detect a statistical difference in pain.

The importance of this study is the novelty of using a sport supplement intervention in competitive athletes of sport modalities characterized by a high prevalence of PT caused by a similar injury mechanism. However, this study is not absent of limitations. Firstly, this study included a small sample size that included only 4 participants in each experimental group, limiting the statistical power of the results presented. Studies focused on female athletes are lower than studies focused on male athletes. Based on this, sex and exclusion criteria were not included. Nevertheless, ovulatory phases during the experimental session weren't controlled, which could be a limitation for a possible interaction with physical performance in female participants. Thirdly, duration of the study could be a limiting factor, because four weeks could reflect neural adaption to physical training but is not sufficient for detecting structural adaptations. Finally, the absence of inclusion of a group that only uses HMB supplementation impairment to analyze the effects of HMB in PT athletes independently of doing a supervised rehabilitation program. Considering all these limitations, this study must be considered as a pilot study and future study must conducted to analyze the effect of an intervention with a higher sample size and duration 


\section{Practical Implications}

Considering that PT sometimes brings the athlete's career to an end [90], the results of this study demonstrate that the combination of different conservative treatments (stretching, eccentric training and ESWT) can optimize rehabilitation with respect to an intervention with less treatment. In addition, the positive effect of the CMJ in the HMBG suggests that it is possible to overcome jumper's knee with a significant change in the sport performance. Consequently, through a nutritional intervention, the return period to the neuromuscular performance required for sport could be reduced.

\section{Conclusions}

The inclusion of eccentric training, selecting a decline squat $\left(25^{\circ} \mathrm{C}\right)$ in combination with stretching and ESWT, has reported increasing concentric muscular strength and concentric muscular power, without changes in perceived pain and body lean mass. Considering the high prevalence of PT in the athletics population and the positive results of the noninvasive treatment of the injury in just a period of 4 weeks, it is recommended to include the combination of these three treatments (eccentric training, stretching and ESWT) in the rehabilitation programs of athletes.

The results of the present study have demonstrated that a nutritional intervention can potentiate the effectiveness of a rehabilitation of PT in athletes; thus, a supplementation with HMB ( $\left.3 \mathrm{~g} \cdot \mathrm{day}^{-1}\right)$ can enhance the power of muscular performance in athletes with PT, optimizing the adaptions of an intervention for the non-invasive treatment of the injury. Nevertheless, due to the small sample size of the present study, this study must be considered as a pilot study. In addition, future studies should analyze the possible usefulness of other sport supplements (i.e., whey protein and creatine) during the rehabilitation programs in athletes with PT.

Author Contributions: Conceptualization, Á.S.-G., J.M.J.-C. and R.D.; methodology, Á.S.-G., J.M.J.-C. and R.D.; formal analysis, R.D.; investigation, Á.S.-G., J.M.J.-C., R.D. and F.M.; data curation, J.M.J.-C., R.D. and A.J.S.-O.; writing-original draft preparation, Á.S.-G., J.M.J.-C. and R.D.; writing-review and editing, J.M.J.-C., R.D. and A.J.S.-O.; visualization, Á.S.-G., J.M.J.-C., F.M., A.J.S.-O. and R.D; supervision, R.D. All authors have read and agreed to the published version of the manuscript.

Funding: This research received no external funding.

Institutional Review Board Statement: The study was conducted according to the guidelines of the Declaration of Helsinki and approved by an Ethics Committee (code: UI1-PI017).

Informed Consent Statement: Informed consent was obtained from all subjects involved in the study.

Conflicts of Interest: The authors declare no conflict of interest.

\section{References}

1. Lian, Ø.B.; Engebretsen, L.; Bahr, R. Prevalence of jumper's knee among elite athletes from different sports: A cross-sectional study. Am. J. Sports Med. 2005, 33, 561-567. [CrossRef]

2. $\quad$ Lian, Ø.; Refsnes, P.E.; Engebretsen, L.; Bahr, R. Performance characteristics of volleyball players with patellar tendinopathy. Am. J. Sports Med. 2003, 31, 408-413. [CrossRef] [PubMed]

3. Hannington, M.; Rio, E.; Padua, D.; Stanley, L.; Berkoff, D.; Edwards, S.; Rudavsky, A.; Cook, J.; Docking, S. Prevalence and impact of patellar tendinopathy on elite basketball athletes: Quantifying injury beyond the time-loss definition. J. Sci. Med. Sport 2017, 20, 17-18. [CrossRef]

4. Blazina, M.E.; Kerlan, R.K.; Jobe, F.W.; Carter, V.S.; Carlson, G.J. Jumper's knee. Orthop. Clin. North Am. 1973, 4, 665-678. [CrossRef]

5. Peers, K.H.E.; Lysens, R.J.J. Patellar tendinopathy in athletes: Current diagnostic and therapeutic recommendations. Sport. Med. 2005, 35, 71-87. [CrossRef] [PubMed]

6. Ferretti, A. Epidemiology of Jumper's Knee. Sport. Med. An Int. J. Appl. Med. Sci. Sport Exerc. 1986, 3, $289-295$.

7. Khan, K.M.; Cook, J.L.; Taunton, J.E.; Bonar, F. Overuse tendinosis, not tendinitis. Part 1: A new paradigm for a difficult clinical problem. Phys. Sportsmed. 2000, 28, 38-48. [CrossRef]

8. Childress, M.A.; Beutler, A. Management of chronic tendon injuries. Am. Fam. Physician 2013, 87, 486-490. 
9. Anitua, E.; Sánchez, M.; Orive, G. Potential of endogenous regenerative technology for in situ regenerative medicine. Adv. Drug Deliv. Rev. 2010, 62, 741-752. [CrossRef]

10. Abat, F.; Diesel, W.J.; Gelber, P.E.; Polidori, F.; Monllau, J.C.; Sanchez-Ibañez, J.M. Effectiveness of the Intratissue Percutaneous Electrolysis $\left(\mathrm{EPI}^{\circledR}\right)$ technique and isoinertial eccentric exercise in the treatment of patellar tendinopathy at two years follow-up. Muscles. Ligaments Tendons J. 2014, 4, 188-193. [CrossRef]

11. Abat, F.; Sánchez-Sánchez, J.L.; Martín-Nogueras, A.M.; Calvo-Arenillas, J.I.; Yajeya, J.; Méndez-Sánchez, R.; Monllau, J.C.; Gelber, P.E. Randomized controlled trial comparing the effectiveness of the ultrasound-guided galvanic electrolysis technique (USGET) versus conventional electro-physiotherapeutic treatment on patellar tendinopathy. J. Exp. Orthop. 2016, 3, 1-8. [CrossRef]

12. Cook, S.D.; Salkeld, S.L.; Popich-Patron, L.S.; Ryaby, J.P.; Jones, D.G.; Barrack, R.L. Improved cartilage repair after treatment with low-intensity pulsed ultrasound. In Proceedings of the Clinical Orthopaedics and Related Research; Lippincott Williams and Wilkins: Philadelphia, PA, USA, 2001.

13. Han, S.H.; Lee, J.W.; Guyton, G.P.; Parks, B.G.; Courneya, J.-P.; Schon, L.C.J. Leonard Goldner Award 2008: Effect of Extracorporeal Shock Wave Therapy on Cultured Tenocytes. Foot Ankle Int. 2009, 30, 93-98. [CrossRef] [PubMed]

14. Gaida, J.E.; Cook, J. Treatment options for patellar tendinopathy: Critical review. Curr. Sports Med. Rep. 2011, 10, 255-270. [CrossRef] [PubMed]

15. Larsson, M.E.H.; Käll, I.; Nilsson-Helander, K. Treatment of patellar tendinopathy-a systematic review of randomized controlled trials. Knee Surgery Sport. Traumatol. Arthrosc. 2012, 20, 1632-1646. [CrossRef]

16. Malliaras, P.; Barton, C.J.; Reeves, N.D.; Langberg, H. Achilles and patellar tendinopathy loading programmes: A systematic review comparing clinical outcomes and identifying potential mechanisms for effectiveness. Sport. Med. 2013, 43, 267-286. [CrossRef] [PubMed]

17. Medeiros, D.M.; Cini, A.; Sbruzzi, G.; Lima, C.S. Influence of static stretching on hamstring flexibility in healthy young adults: Systematic review and meta-analysis. Physiother. Theory Pract. 2016, 32, 438-445. [CrossRef] [PubMed]

18. Artrong, R.B.; Warren, G.L.; Warren, J.A. Mechanisms of Exercise-Induced Muscle Fibre Injury. Sport. Med. 1991, 12, 184-207. [CrossRef]

19. Lieber, R.L. Skeletal Muscle Structure, Function, and Plasticity; Wolters Kluwer Health Adis (ESP): Philadelphia, PA, USA, 2011; ISBN 9780781775939.

20. Nosaka, K.; Sakamoto, K.; Newton, M.; Sacco, P. The repeated bout effect of reduced-load eccentric exercise on elbow flexor muscle damage. Eur. J. Appl. Physiol. 2001, 85, 34-40. [CrossRef]

21. Langberg, H.; Kongsgaard, M. Eccentric training in tendinopathy-More questions than answers: Editorial. Scand. J. Med. Sci. Sport. 2008, 18, 541-542. [CrossRef]

22. Rees, J.D.; Wolman, R.L.; Wilson, A. Eccentric exercises; why do they work, what are the problems and how can we improve them? Br. J. Sports Med. 2009, 43, 242-246. [CrossRef] [PubMed]

23. Dimitrios, S.; Pantelis, M.; Kalliopi, S. Comparing the effects of eccentric training with eccentric training and static stretching exercises in the treatment of patellar tendinopathy. A controlled clinical trial. Clin. Rehabil. 2012, 26, 423-430. [CrossRef] [PubMed]

24. Schwartz, A.; Watson, J.N.; Hutchinson, M.R. Patellar Tendinopathy. Sports Health 2015, 7, 415-420. [CrossRef] [PubMed]

25. Chung, B.; Wiley, J.P. Extracorporeal shockwave therapy: A review. Sport. Med. 2002, 32, 851-865. [CrossRef]

26. Di Meglio, F.; Sacco, A.M.; Belviso, I.; Romano, V.; Sirico, F.; Loiacono, C.; Palermi, S.; Pempinello, C.; Montagnani, S.; Nurzynska, D.; et al. Influence of supplements and drugs used for the treatment of musculoskeletal disorders on adult human tendon-derived stem cells. Muscles. Ligaments Tendons J. 2020, 10, 376-384. [CrossRef]

27. Loiacono, C.; Palermi, S.; Massa, B.; Belviso, I.; Romano, V.; Di Gregorio, A.; Sirico, F.; Sacco, A.M. Tendinopathy: Pathophysiology, Therapeutic Options, and Role of Nutraceutics. A Narrative Literature Review. Medicina 2019, 55, 447. [CrossRef] [PubMed]

28. Tipton, K.D. Dietary strategies to attenuate muscle loss during recovery from injury. Nestle Nutr. Inst. Workshop Ser. 2013, 75, 51-61.

29. Tipton, K.D. Nutritional Support for Exercise-Induced Injuries. Sport. Med. 2015, 45, 93-104. [CrossRef] [PubMed]

30. Rawson, E.S.; Miles, M.P.; Larson-Meyer, D.E. Dietary supplements for health, adaptation, and recovery in athletes. Int. J. Sport Nutr. Exerc. Metab. 2018, 28, 188-199. [CrossRef]

31. Durkalec-Michalski, K.; Jeszka, J. The efficacy of a $\beta$-hydroxy- $\beta$-methylbutyrate supplementation on physical capacity, body composition and biochemical markers in elite rowers: A randomised, double-blind, placebocontrolled crossover study. J. Int. Soc. Sports Nutr. 2015, 12, 31. [CrossRef] [PubMed]

32. Eley, H.L.; Russell, S.T.; Baxter, J.H.; Mukerji, P.; Tisdale, M.J. Signaling pathways initiated by $\beta$-hydroxy- $\beta$-methylbutyrate to attenuate the depression of protein synthesis in skeletal muscle in response to cachectic stimuli. Am. J. Physiol. Endocrinol. Metab. 2007, 293, E923-E931. [CrossRef]

33. Schiaffino, S.; Dyar, K.A.; Ciciliot, S.; Blaauw, B.; Sandri, M. Mechanisms regulating skeletal muscle growth and atrophy. FEBS J. 2013, 280, 4294-4314. [CrossRef] [PubMed]

34. Kornasio, R.; Riederer, I.; Butler-Browne, G.; Mouly, V.; Uni, Z.; Halevy, O. $\beta$-hydroxy- $\beta$-methylbutyrate (HMB) stimulates myogenic cell proliferation, differentiation and survival via the MAPK/ERK and PI3K/Akt pathways. Biochim. Biophys. Acta Mol. Cell Res. 2009, 1793, 755-763. [CrossRef]

35. Smith, H.J.; Mukerji, P.; Tisdale, M.J. Attenuation of proteasome-induced proteolysis in skeletal muscle by \{beta\}-hydroxy-\{beta\}methylbutyrate in cancer-induced muscle loss. Cancer Res. 2005, 65, 277-283. [PubMed] 
36. Nissen, S.L.; Abumrad, N.N. Nutritional role of the leucine metabolite $\beta$-hydroxy $\beta$-methylbutyrate (HMB). J. Nutr. Biochem. 1997, 8, 300-311. [CrossRef]

37. Sanchez-Martinez, J.; Santos-Lozano, A.; Garcia-Hermoso, A.; Sadarangani, K.P.; Cristi-Montero, C. Effects of beta-hydroxy-betamethylbutyrate supplementation on strength and body composition in trained and competitive athletes: A meta-analysis of randomized controlled trials. J. Sci. Med. Sport 2018, 21, 727-735. [CrossRef] [PubMed]

38. Holland, B.M.; Roberts, B.M.; Krieger, J.W.; Schoenfeld, B.J. Does HMB Enhance Body Composition in Athletes? A Systematic Review and Meta-analysis. J. Strength Cond. Res. 2019. [CrossRef]

39. Wilson, J.M.; Lowery, R.P.; Joy, J.M.; Andersen, J.C.; Wilson, S.M.C.; Stout, J.R.; Duncan, N.; Fuller, J.C.; Baier, S.M.; Naimo, M.A.; et al. The effects of 12 weeks of beta-hydroxy-beta-methylbutyrate free acid supplementation on muscle mass, strength, and power in resistance-trained individuals: A randomized, double-blind, placebo-controlled study. Eur. J. Appl. Physiol. 2014, 114, 1217-1227. [CrossRef] [PubMed]

40. Oktaviana, J.; Zanker, J.; Vogrin, S.; Duque, G. The Effect of $\beta$-Hydroxy- $\beta$-Methylbutyrate (HMB) on Sarcopenia and Functional Frailty in Older Persons: A Systematic Review. J. Nutr. Health Aging 2019, 23, 145-150. [CrossRef]

41. Rossi, A.P.; D’Introno, A.; Rubele, S.; Caliari, C.; Gattazzo, S.; Zoico, E.; Mazzali, G.; Fantin, F.; Zamboni, M. The Potential of $\beta$-Hydroxy- $\beta$-Methylbutyrate as a New Strategy for the Management of Sarcopenia and Sarcopenic Obesity. Drugs Aging 2017, 34, 833-840. [CrossRef]

42. Rio, E.; Kidgell, D.; Purdam, C.; Gaida, J.; Moseley, G.L.; Pearce, A.J.; Cook, J. Isometric exercise induces analgesia and reduces inhibition in patellar tendinopathy. Br. J. Sports Med. 2015, 49, 1277-1283. [CrossRef] [PubMed]

43. Kaczka, P.; Michalczyk, M.M.; Jastrzab, R.; Gawelczyk, M.; Kubicka, K. Mechanism of action and the effect of beta-hydroxy-betamethylbutyrate (HMB) supplementation on different types of physical performance-A systematic review. J. Hum. Kinet. 2019, 68, 211-222. [CrossRef]

44. Holden, S.; Lyng, K.; Graven-Nielsen, T.; Riel, H.; Olesen, J.L.; Larsen, L.H.; Rathleff, M.S. Isometric exercise and pain in patellar tendinopathy: A randomized crossover trial. J. Sci. Med. Sport 2020, 23, 208-214. [CrossRef] [PubMed]

45. Haefeli, M.; Elfering, A. Pain assessment. Eur. Spine J. 2006, 15 (Suppl. 1), S17-S24. [CrossRef]

46. Al-Abbad, H.; Simon, J.V. The effectiveness of extracorporeal shock wave therapy on chronic Achilles tendinopathy: A systematic review. Foot Ankle Int. 2013, 34, 33-41. [CrossRef]

47. Kyle, U.G.; Bosaeus, I.; De Lorenzo, A.D.; Deurenberg, P.; Elia, M.; Gómez, J.M.; Heitmann, B.L.; Kent-Smith, L.; Melchior, J.C.; Pirlich, M.; et al. Bioelectrical impedance analysis-Part I: Review of principles and methods. Clin. Nutr. 2004, 23, 1226-1243. [CrossRef]

48. Visentini, P.J.; Khan, K.M.; Cook, J.L.; Kiss, Z.S.; Harcourt, P.R.; Wark, J.D. The VISA score: An index of severity of symptoms in patients with jumper's knee (Patellar Tendinosis). J. Sci. Med. Sport 1998, 1, 22-28. [CrossRef]

49. Balsalobre-Fernández, C.; Tejero-González, C.M.; Del Campo-Vecino, J.; Bavaresco, N. The concurrent validity and reliability of a low-cost, high-speed camera-based method for measuring the flight time of vertical jumps. J. Strength Cond. Res. 2014, 28, 528-533. [CrossRef]

50. Pérez-Castilla, A.; Piepoli, A.; Delgado-García, G.; Garrido-Blanca, G.; García-Ramos, A. Reliability and concurrent validity of seven commercially available devices for the assessment of movement velocity at different intensities during the bench press. $J$. Strength Cond. Res. 2019, 33, 1258-1265. [CrossRef]

51. Maté-Muñoz, J.L.; Lougedo, J.H.; Garnacho-Castaño, M.V.; Veiga-Herreros, P.; Lozano-Estevan, M.D.C.; García-Fernández, P.; de Jesús, F.; Guodemar-Pérez, J.; San Juan, A.F.; Domínguez, R. Effects of $\beta$-alanine supplementation during a 5-week strength training program: A randomized, controlled study. J. Int. Soc. Sports Nutr. 2018, 15, 19. [CrossRef] [PubMed]

52. Sascha, G.; Künzell, S. Reliabilität eines 5-RM krafttests für den gesundheits- und fitnesssport. Dtsch. Z. Sportmed. 2014, 65, 314-317.

53. Ferguson, C.J. An Effect Size Primer: A Guide for Clinicians and Researchers. Prof. Psychol. Res. Pract. 2009, 40, 532-538. [CrossRef]

54. Bahr, R.; Fossan, B.; Løken, S.; Engebretsen, L. Surgical treatment compared with eccentric training for patellar tendinopathy (jumper's knee): A randomized, controlled trial. J. Bone Jt. Surg. Ser. A 2006, 88, 1689-1698. [CrossRef]

55. Romero-Rodriguez, D.; Gual, G.; Tesch, P.A. Efficacy of an inertial resistance training paradigm in the treatment of patellar tendinopathy in athletes: A case-series study. Phys. Ther. Sport 2011, 12, 43-48. [CrossRef]

56. Biernat, R.; Trzaskoma, Z.; Trzaskoma, Ł.; Czaprowski, D. Rehabilitation protocol for patellar tendinopathy applied among 16-to 19-year old volleyball players. J. Strength Cond. Res. 2014, 28, 43-52. [CrossRef]

57. Frohm, A.; Halvorsen, K.; Thorstensson, A. Patellar tendon load in different types of eccentric squats. Clin. Biomech. 2007, 22, 704-711. [CrossRef] [PubMed]

58. Baker, D.; Nance, S.; Moore, M. The Load That Maximizes the Average Mechanical Power Output during Jump Squats in Power-Trained Athletes. J. Strength Cond. Res. 2001, 15, 92-97.

59. Cronin, J.; Sleivert, G. Challenges in understanding the influence of maximal power training on improving athletic performance. Sport. Med. 2005, 35, 213-234. [CrossRef]

60. Astrom, M.; Arvidson, T. Alignment and joint motion in the normal foot. J. Orthop. Sports Phys. Ther. 1995, 22, 216-222. [CrossRef] [PubMed] 
61. Helland, C.; Bojsen-Møller, J.; Raastad, T.; Seynnes, O.R.; Moltubakk, M.M.; Jakobsen, V.; Visnes, H.; Bahr, R. Mechanical properties of the patellar tendon in elite volleyball players with and without patellar tendinopathy. Br. J. Sports Med. 2013, 47, 862-868. [CrossRef]

62. Lee, W.C.; Zhang, Z.J.; Masci, L.; Ng, G.Y.F.; Fu, S.N. Alterations in mechanical properties of the patellar tendon is associated with pain in athletes with patellar tendinopathy. Eur. J. Appl. Physiol. 2017, 117, 1039-1045. [CrossRef] [PubMed]

63. Pearson, S.J.; Onaimbele, G.N.L. Influence of time of day on tendon compliance and estimations of voluntary activation levels. Muscle and Nerve 2006, 33, 792-800. [CrossRef] [PubMed]

64. Taş, S.; Yilmaz, S.; Onur, M.R.; Soylu, A.R.; Altuntaş, O.; Korkusuz, F. Patellar tendon mechanical properties change with gender, body mass index and quadriceps femoris muscle strength. Acta Orthop. Traumatol. Turc. 2017, 51, 54-59. [CrossRef]

65. Troy Blackburn, J.; Bell, D.R.; Norcross, M.F.; Hudson, J.D.; Engstrom, L.A. Comparison of hamstring neuromechanical properties between healthy males and females and the influence of musculotendinous stiffness. J. Electromyogr. Kinesiol. 2009, 19, e362-e369. [CrossRef] [PubMed]

66. Kawakami, Y.; Kubo, K.; Kanehisa, H.; Fukunaga, T. Effect of series elasticity on isokinetic torque-angle relationship in humans. Eur. J. Appl. Physiol. 2002, 87, 381-387. [PubMed]

67. Crossley, K.M.; Thancanamootoo, K.; Metcalf, B.R.; Cook, J.L.; Purdam, C.R.; Warden, S.J. Clinical features of patellar tendinopathy and their implications for rehabilitation. J. Orthop. Res. 2007, 25, 1164-1175. [CrossRef]

68. Kannus, P. Etiology and pathophysiology of chronic tendon disorders in sports. Scand. J. Med. Sci. Sport. 1997, 7, 78-85. [CrossRef] [PubMed]

69. Abate, M.; Gravare Silbernagel, K.; Siljeholm, C.; Di Iorio, A.; De Amicis, D.; Salini, V.; Werner, S.; Paganelli, R. Pathogenesis of tendinopathies: Inflammation or degeneration? Arthritis Res. Ther. 2009, 11, 235. [CrossRef] [PubMed]

70. Heinemeier, K.M.; Kjaer, M. In vivo investigation of tendon responses to mechanical loading. J. Musculoskelet. Neuronal Interact. 2011, 11, 115-123.

71. Kongsgaard, M.; Kovanen, V.; Aagaard, P.; Doessing, S.; Hansen, P.; Laursen, A.H.; Kaldau, N.C.; Kjaer, M.; Magnusson, S.P. Corticosteroid injections, eccentric decline squat training and heavy slow resistance training in patellar tendinopathy. Scand. J. Med. Sci. Sports 2009, 19, 790-802. [CrossRef] [PubMed]

72. Gómez Díaz, J. Effectiveness of eccentric exercise in patellar tendinopathy. Literature review. Arch. Med. Deport. 2016, 33, 59-66.

73. Witvrouw, E.; Bellemans, J.; Lysens, R.; Danneels, L.; Cambier, D. Intrinsic risk factors for the development of patellar tendinitis in an athletic population: A two-year prospective study. Am. J. Sports Med. 2001, 29, 190-195. [CrossRef] [PubMed]

74. Cook, J.L.; Kiss, Z.S.; Khan, K.M.; Purdam, C.R.; Webster, K.E. Anthropometry, physical performance, and ultrasound patellar tendon abnormality in elite junior basketball players: A cross-sectional study. Br. J. Sports Med. 2004, 38, 206-209. [CrossRef]

75. Piva, S.R.; Goodnite, E.A.; Childs, J.D. Strength around the hip and flexibility of soft tissues in individuals with and without patellofemoral pain syndrome. J. Orthop. Sports Phys. Ther. 2005, 35, 793-801. [CrossRef]

76. Palermi, S.; Massa, B.; Vecchiato, M.; Mazza, F.; De Blasiis, P.; Romano, A.M.; Di Salvatore, M.G.; Della Valle, E.; Tarantino, D.; Ruosi, C.; et al. Indirect Structural Muscle Injuries of Lower Limb: Rehabilitation and Therapeutic Exercise. J. Funct. Morphol. Kinesiol. 2021, 6, 75. [CrossRef]

77. Mann, K.J.; Edwards, S.; Drinkwater, E.J.; Bird, S.P. A lower limb assessment tool for athletes at risk of developing patellar tendinopathy. Med. Sci. Sports Exerc. 2013, 45, 527-533. [CrossRef]

78. Mendonça, L.D.; Verhagen, E.; Bittencourt, N.F.N.; Gonçalves, G.G.P.; Ocarino, J.M.; Fonseca, S.T. Factors associated with the presence of patellar tendon abnormalities in male athletes. J. Sci. Med. Sport 2016, 19, 389-394. [CrossRef] [PubMed]

79. Wang, C.J.; Ko, J.Y.; Chan, Y.S.; Weng, L.H.; Hsu, S.L. Extracorporeal shockwave for chronic patellar tendinopathy. Am. J. Sports Med. 2007, 35, 972-978. [CrossRef] [PubMed]

80. Visco, V.; Vulpiani, M.C.; Torrisi, M.R.; Ferretti, A.; Pavan, A.; Vetrano, M. Experimental studies on the biological effects of extracorporeal shock wave therapy on tendon models. A review of the literature. Muscles. Ligaments Tendons J. 2014, 4, 357-361. [CrossRef]

81. Maier, M.; Averbeck, B.; Milz, S.; Refior, H.J.; Schmitz, C. Substance P and prostaglandin E2 release after shock wave application to the rabbit femur. Clin. Orthop. Relat. Res. 2003, 406, 237-245. [CrossRef]

82. Knitter, A.E.; Panton, L.; Rathmacher, J.A.; Petersen, A.; Sharp, R. Effects of $\beta$-hydroxy- $\beta$-methylbutyrate on muscle damage after a prolonged run. J. Appl. Physiol. 2000, 89, 1340-1344. [CrossRef]

83. Paddon-Jones, D.; Keech, A.; Jenkins, D. Short-term $\beta$-hydroxy- $\beta$-methylbutyrate supplementation does not reduce symptoms of eccentric muscle damage. Int. J. Sport Nutr. 2001, 11, 442-450. [CrossRef] [PubMed]

84. Van Someren, K.A.; Edwards, A.J.; Howatson, G. Supplementation with $\beta$-hydroxy- $\beta$-methylbutyrate (hmb) and $\alpha$-ketoisocaproic acid (KIC) reduces signs and symptoms of exercise-induced muscle damage in man. Int. J. Sport Nutr. Exerc. Metab. 2005, 15, 413-424. [CrossRef] [PubMed]

85. Nissen, S.; Sharp, R.; Ray, M.; Rathmacher, J.A.; Rice, D.; Fuller, J.C.; Connelly, A.S.; Abumrad, N. Effect of leucine metabolite $\beta$-hydroxy- $\beta$-methylbutyrate on muscle metabolism during resistance-exercise training. J. Appl. Physiol. 1996, 81, $2095-2104$. [CrossRef]

86. Allen, D.G.; Whitehead, N.P.; Yeung, E.W. Mechanisms of stretch-induced muscle damage in normal and dystrophic muscle: Role of ionic changes. J. Physiol. 2005, 567, 723-735. [CrossRef] 
87. Tsuchiya, Y.; Hirayama, K.; Ueda, H.; Ochi, E. Two and Four Weeks of $\beta$-Hydroxy- $\beta$-Methylbutyrate (HMB) Supplementations Reduce Muscle Damage Following Eccentric Contractions. J. Am. Coll. Nutr. 2019, 38, 373-379. [PubMed]

88. Reeves, N.D.; Maganaris, C.N.; Ferretti, G.; Narici, M.V. Influence of 90-day simulated microgravity on human tendon mechanical properties and the effect of resistive countermeasures. J. Appl. Physiol. 2005, 98, 2278-2286. [CrossRef]

89. Seynnes, O.R.; De Boer, M.; Narici, M.V. Early skeletal muscle hypertrophy and architectural changes in response to high-intensity resistance training. J. Appl. Physiol. 2007, 102, 368-373. [CrossRef]

90. Jonsson, P.; Alfredson, H. Superior results with eccentric compared to concentric quadriceps training in patients with jumper's knee: A prospective randomised study. Br. J. Sports Med. 2005, 39, 847-850. [CrossRef] [PubMed] 